\title{
Grafit Nanoplaka Takviyeli Ultra Yüksek Molekül Ağırlıklı Polietilen Tabanlı Nano-Kompozit Malzeme Geliştirilmesi ve Karakterizasyonu
}

\author{
Development and Characterization of Graphite Nanoplate \\ Reinforced Ultra High Molecular Weight Polyethylene \\ Based Nano-Composite Materials
}

Lütfiye ALTAY1 ${ }^{\oplus}$, Metehan ATAGÜR $^{2} \odot$, Müslüm ERBEKTAŞ ${ }^{3} \odot$ Mehmet SARIKANAT $^{1 *}$

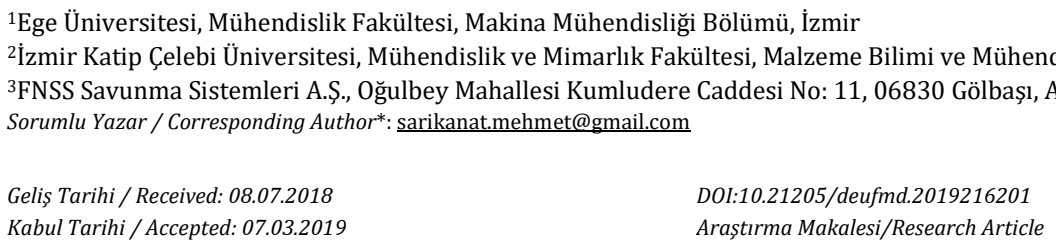

Atıfșekli/How to cite: ALTAY, L., ATAGÜR, M., ERBEKTAŞ, M., SARIKANAT, M. (2019). Grafit Nanoplaka Takviyeli Ultra Yüksek Molekül Ağırlıklı Polietilen Tabanlı Nano-Kompozit Malzeme Geliştirilmesi ve Karakterizasyonu. DEUFMD, 21(62), 323-330.

Öz

Bu çalıșmada, 0, 0.02, 0.05, 0.1 ve \%0.15 ağırlık oranlarında grafit ( $\mathrm{Gr}$ ) ve ultra yüksek molekül ağırlıklı polietilen (UHMWPE) etanol içerisinde dağıtılarak grafit takviyeli UHMWPE nano-kompozit malzemeler üretilmiştir. UHMWPE ve Gr takviyeli kompozit malzemelerin termal performansları termogravimetrik analizler ile tespit edilmiştir. ULMWPE ve kompozit malzemelerin kimyasal yapısı Fourier Dönüşümlü Kızılötesi Spektroskopi ile incelenmiştir. Bunlara ek olarak; Gr katkısının polimerin çekme özellikleri, yüzey pürüzlülüğü, yoğunluk ve sertlik üzerine etkileri incelenmiștir. Bu sonuçlara göre, Gr eklendikçe kompozit malzemelerin maksimum bozunma sıcaklıkları fazla etkilenmemek ile birlikte elastisite modülü ve sertlik artmakta, yüzey pürüzlülüğü düşmektedir. Çekme dayanımı ise ağırlıkça \%0.1 Gr katkı oranına kadar artmakta bu orandan sonra düşmektedir. Anahtar Kelimeler: Kompozit malzemeler,Grafit, UHMWPE

\section{Abstract}

In this study, graphite filled ultra high molecular weight polyethylene nano-composite materials were produced by dispersing $0,0.02,0.05,0.1$ and $0.15 \mathrm{wt} \%$ graphite (Gr) and ultra high molecular weight polyethylene(UHMWPE) in ethanol. The thermal performances of UHMWPE and Gr filled composite materials were determined by thermogravimetric analysis. The chemical structure of UHMWPE and composite materials was investigated by Fourier Transform Infrared Spectroscopy. Additionally; the effects of $\mathrm{Gr}$ on the tensile properties, surface roughness, density and hardness of polymer were investigated. According to these results, as the graphite is added, the maximum degradation temperatures of the composite materials are not affected much, and the modulus of elasticity and hardness increase and the surface roughness decreases. The tensile strength increased with the addition of Gr up to $0.1 \mathrm{wt} \%$, but decreased with the further increase of Gr weight fraction.

Keywords: Composite materials, Graphite, UHMWPE 


\section{Giriș}

Bir milyonu aşan molekül ağırlığına, yüksek darbe mukavemetine, iyi biyouyumluluk özelliğine ve düşük sürtünme katsayısına sahip ultra yüksek molekül ağırlıklı polietilen (UHMWPE) yüksek performans gerektiren biyomedikal, savunma, yataklama, boru hatları vb. çeşitli uygulama alanlarında yaygın olarak kullanılmaktadır [1-8]. Özellikle biyomedikal sektöründe, insan vücudundaki suni eklemler için yaygın olarak kullanımı bulunmaktadır.[9]. UHMWPE' nin biyomedikal sektöründe kullanımı esnasında düşük yüzey sertliği ve zayıf aşınma dayanımına sahip olması nedeniyle aşınma esnasında çıkan parçacıklar kemik kaybına, eklem gevșemesine ve yapay eklemlerin ömrünü sınırlayan kemik erimesine yol açmaktadır [10-14].

Günümüzde; ultra yüksek molekül ağırlıklı polietilenin sürünme davranışını, aşınma direncini, mekanik özelliklerini ve yüzey sertliğini iyileştirme konusu üzerine bir çok çalışma yapılmaktadır. UHMWPE'nin aşınma ve mekanik özelliklerini iyileștirmenin bir yolu inorganik takviye/dolgu malzemelerinin kullanılarak kompozit malzemelerin üretilmesidir [9]. Bu kompozit malzemelerin geliştirilmesi üzerine bir çok çalışma yapılmıştır. Literatürde, kompozitlerde dolgu/takviye malzemeleri olarak kuvars [15], kaolin [16], zirkonyum parçacıkları [17] ve farklı şekillere sahip karbon tabanlı [14, 18-21] takviye/dolgular kullanılmaktadır. Hem endüstriyel hem de ortopedik uygulamalar için UHMWPE'nin tribolojik özelliklerini geliştirmenin yolu matrise nano parçacıklar [2223], nanofiber ve nanotüpler [25] eklemektir. Özellikle, iki boyutlu karbon nanoyapısına sahip olan grafen, yüksek Young modülü (0,5-1 TPA), yüksek çekme dayanımı $(130 \mathrm{GPa})$ ve mükemmel esnekliği sebebiyle çeşitli polimer kompozitlerde uygulama alanı bulmaktadır [14, 26-28]. Son yıllarda, farklı yöntemlerle üretilen grafen ve grafen oksit takviyeli polimerik kompozitler üzerine bir çok çalışma yapılmıștır. $\mathrm{Bu}$ çalıșmalarda grafenin polimer içine az miktarda katılmasıyla birlikte ana polimerin mekanik, aşınma, elektriksel ve termal özelliklerinin iyileștiği belirtilmiștir [13, 29-34].

Karbon lifi, grafit nanoplakalar,karbon siyahı ve karbon nanotüpleri de dahil olmak üzere çeşitli karbon malzemeleri, iyi termal kararlılık, düşük kayma mukavemeti, yüzey tutunması ve yağlama özellikleri nedeniyle UHMWPE'de dolgu maddesi olarak incelenmiştir.

Bu çalıșmada, grafit nanoplakaların UHMWPE tabanlı kompozitlerde kullanımı ile elde edilen kompozit malzemelerin yüzey pürüzlülüğüne, sertlik ve aşınma özelliklerine etkisinin araştırılması; dolayısı ile özellikle biyomedikal uygulamalardaki kullanılabilirliliğinin incelenmesi amaçlanmıştır. $\mathrm{Bu}$ amaç doğrultusunda farklı ağırlık oranlarında grafit nanoplakalar $(\mathrm{Gr})$ ile takviyelendirilmiş UHMWPE kompozit malzemeler üretilmiștir. Daha sonra bu kompozit malzemelerin çekme testleri, mikrosertlik testleri, termogravimektrik analizleri, Fourier Dönüşümlü Kızılötesi (FT-IR) Spektroskopileri ve Taramalı Elekton Mikroskobu (SEM) analizleri yapılmıștır.

\section{Malzeme ve Metot}

\subsection{Malzemeler}

$\mathrm{Bu}$ çalışmada, ALDRICH (Kat. No. $\mathrm{xxxx}$ ) UHMWPE ve takviye malzemesi olarak GRAFEN A.Ş. firmasından sağlanan grafit nanoplaka kullanılmıștır.

\subsection{UHMWPE ve Kompozit Film Üretimi}

$\mathrm{Bu}$ çalışmada, ilk olarak UHMWPE etanol içerisinde mekanik olarak karıştırıldıktan sonra $0,0.02,0.05,0.1$ ve $\% 0.15$ ağırlık oranlarında grafit nanoplaka eklenerek ultrasonik karıştırıcıda 70 Hertz'de $30 \mathrm{dk}$ boyunca karıștırılarak homojen bir karışım elde edilmiştir. Daha sonra bu karıșımlar petri kabına dökülerek $170{ }^{\circ} \mathrm{C}^{\prime}$ de firın petri çerisindeki etanolün uçması ve UHMWPE'nin erimesi sağlanmıştır. Elde edilen $1 \mathrm{~mm}$ kalınlığındaki filmler (PE, PE0.02Gr, PE0.05Gr, PE0.1Gr, PE0.15Gr) petri kabından çıkarılarak grafit nanoplaka takviyeli kompozit malzemeler elde edilmiştir. Petri içerisinde kompozit film üretimi aşamaları Şekil 1'de gösterilmektedir.

\subsection{Karakterizasyon}

\section{Yoğunluk Ölçümü}

Numunelerin yoğunluk ölçümleri ASTM D792 standardına göre yoğunluk ölçüm cihazı (Densimeter MD-300S, Japonya) kullanılarak yapılmıștır. 


\section{FT-IR Analizi}

Kompozit malzemelerin FT-IR analizleri 500$3500 \mathrm{~cm}^{-1}$ dalga sayısı aralı̆̆ında yapılmıștır (Perkin Elmer 100).

\section{Çekme Deneyi}

UHMWPE ve grafit takviyeli UHMWPE kompozit numunelerin mekanik özellikleri oda sıcaklığında $5 \mathrm{kN}$ yük hücresine sahip Shimadzu Autograph AG-IS serisi üniversal test cihazı (Shimadzu Autograph AG-IS Universal testing machine, Japonya) kullanılarak ASTM D638-10 standardına göre tespit edilmiştir. Deney yapılırken video ekstensiyometre (SHIMADZU temazsız video ekstensiyometre DVE-101/201) kullanılmıștır. Bütün deney numunleri $50 \mathrm{~mm} / \mathrm{dk}$ çekme hızı ile test edilmiștir. Her bir deney grubu için 7 adet deney gerçekleştirilmiştir. Her bir numunenin çekme dayanımı, elastisite modülü ve kopmadaki birim şekil değiştirme değerleri incelenmiştir.

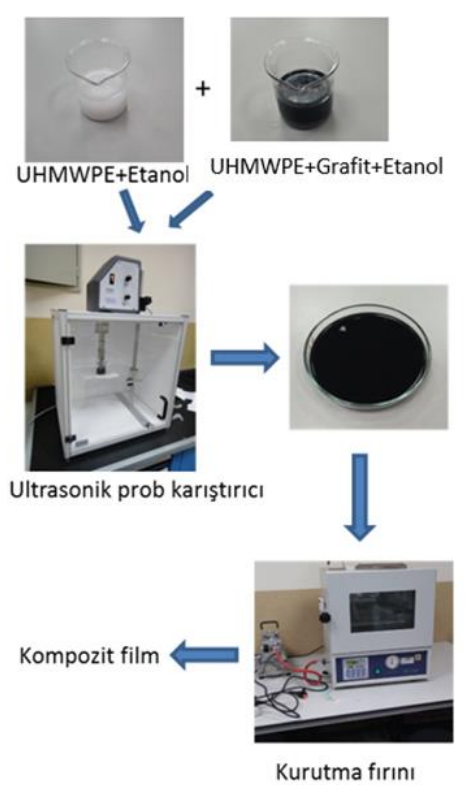

Şekil 1. Kompozit Film Üretimi

\section{Sertlik Deneyi}

UHMWPE ve grafit takviyeli UHMWPE kompozit malzemelerin sertlikleri 10 gr yük altında mikrosertlik cihazı (Shimadzu HMV-G20 mikrosertlik cihazı) ile ölçülmüștür.

\section{Yüzey Pürüzlülük Değerlerinin Ölçülmesi}

UHMWPE ve grafit takviyeli UHMWPE kompozit malzemelerin yüzey pürüzlülük ölçümleri yüzey pürüzlülük ölçüm cihazıyla (Mitutoyo Surftest SJ301) yapılmıştır. Yüzey pürüzlülük ölçümleri her numune için üç ayrı noktadan yapılmıș ve ortalama pürüzlülük değeri alınmıştır.

\section{Termogravimetrik Analiz (TGA)}

UHMWPE ve grafit takviyeli UHMWPE kompozit malzemelerin termogravimetrik analizleri 30$600{ }^{\circ} \mathrm{C}$ sıcaklık aralığında $10{ }^{\circ} \mathrm{C} / \mathrm{dk}$ ısıtma hızında nitrojen ortamında TGAQ500 cihazı kullanılarak (TA Instruments) gerçekleștirilmiştir.

Taramalı Elektron Mikroskobu (SEM) Analizleri

UHMWPE ve grafit takviyeli UHMWPE kompozit malzemelerin çekme deneyi sonucunda elde edilen kırılma yüzeyleri taramalı elektron mikroskobu (Carl Zeiss 300VP, Almanya) kullanarak incelenmiștir.

\section{Bulgular ve Tartışma}

\subsection{Yoğunluk Tayini}

UHMWPE ve grafit içeren UHMWPE kompozitlerin ASTM D792 standardına göre ölçülen yoğunluk değerleri Şekil 2'de verilmiştir. Sonuçlara göre saf PE malzemenin yoğunluk değeri $0.95 \mathrm{~g} / \mathrm{cm}^{3}$ olarak belirlenirken grafit nanoplaka eklendikçe kompozit malzemenin yoğunluk değerleri yükselmektedir. PE içerisine ağırlıkça $\% 0.02, \quad \% 0.05, \quad \% 0.1$ ve $\% 0.15$ oranlarında $\mathrm{Gr}$ eklendikçe yoğunluk değerleri sirasiyla $0.98,1.01,1.08$ ve $1.14 \mathrm{~g} / \mathrm{cm}^{3}$ olarak tespit edilmiştir. $\mathrm{Bu}$ durum grafitin yoğunluğunun PE'nin yoğunluğundan daha yüksek olmasından kaynaklanmaktadır. Yang ve arkadaşları (2012) grafenin yoğunluğunu 2.2 $\mathrm{gr} / \mathrm{cm}^{3}$ olarak ölçmüşlerdir[1]. 


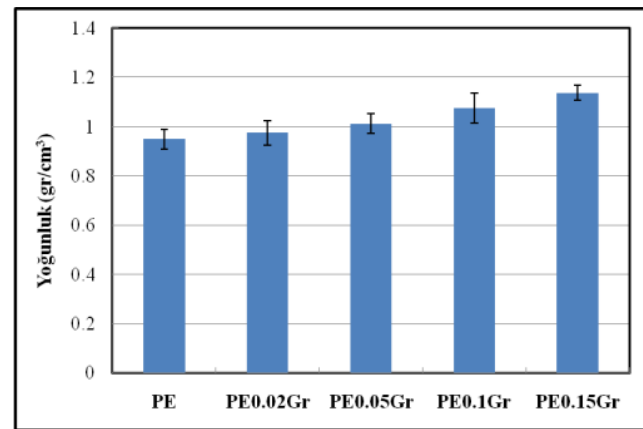

Şekil 2. PE, PE0.02Gr, PE0.05Gr, PE0.1Gr ve PE0.15Gr kompozit malzemelerin yoğunluk değerleri

\subsection{FT-IR Analiz Sonuçları}

Şekil 3'de PE, PE0.02Gr, PE0.05Gr, PE0.1Gr ve PE0.15Gr'nin FT-IR analizi sonuçları gösterilmektedir. 2848 ve $2916 \mathrm{~cm}^{-1}$ pikleri sirasıyla $\mathrm{CH}_{2}$ ve $\mathrm{CH}_{3}$ gruplarının simetrik ve asimetrik bağ gerilmelerinin sonucu olarak ortaya çıkabilmektedir. $1472 \mathrm{~cm}^{-1}$ piki $\mathrm{CH}_{2}$ ya da CH3 deformasyonlarına, $718 \mathrm{~cm}^{-1}$ ve $730 \mathrm{~cm}^{-1}$ pikleri ise $\mathrm{CH}_{2}-\mathrm{CH}_{2}$ grupları arası salınıma işaret etmekte olup tüm numunelerde gözlemlenmiștir. Şekil 3' den de görüleceği gibi grafit takviyesinin etkisi $1715 \mathrm{~cm}^{-1}$ piki incelendiğinde anlaşılmaktadır. PE numunesinde olmayan bu pik grafit eklendikçe artmaktadır. $1077 \mathrm{~cm}^{-1}$ pikin O-C molekül yapısını temsil ettiği düşünülmekte olup grafit eklenmesiyle birlikte bu pikte kayda değer değișiklikler gözlenmemiștir [42].

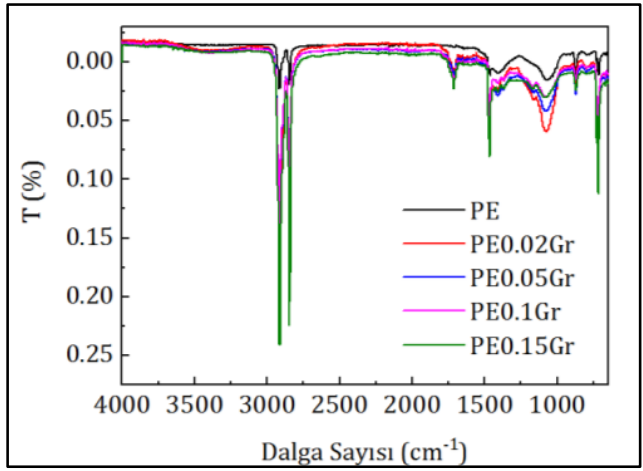

Şekil 3. PE, PE0.02Gr, PE0.05Gr, PE0.1Gr ve PE0.15Gr filmlerin FT-IR spektrumları

\subsection{Cekme Testi}

UHMWPE ve grafit takviyeli UHMWPE kompozit malzemelerin çekme dayanımları ve çekme modülleri Şekil 4 ve 5'de verilmiştir. Şekil 4'de görüldüğü üzere PE, PE0.02Gr, PE0.05Gr, $\mathrm{PE} 0.1 \mathrm{Gr}$ ve $\mathrm{PE} 0.15 \mathrm{Gr}$ filmlerinin çekme dayanımları sırasıyla 16.72, 17.51, 19.54, 21.15 ve $17.89 \mathrm{MPa}$ olarak bulunmuștur. Bu sonuçlara göre ağırlıkça \%0.1 grafit katkısına kadar çekme dayanımı artış göstermektedir. Bunun sebebi grafit nanoplakaların pürüzlü ve buruşuk bir yüzeye sahip olmasından dolayı matris etrafını sararak daha iyi bir mekanik kitlenme sağlayarak daha iyi kuvvet iletimi sağlanmasıdır [2]. Ancak bu orandan sonra çekme dayanımı düşüş göstermektedir. bunun sebebi daha yüksek oranlarda grafit yüklemesinin polimer içerisinde istenilen düzeyde homojen dağıtılamaması olarak söylenebilir. Şekil 5'e göre çekme modülü grafit yüklemesi ile birlikte artmaktadır. Kompozit malzeme üretiminde kullanılan UHMWPE malzemenin elastisite modülü $825 \mathrm{MPa}$ iken ağırlıkça \%0.15 grafit yüklenmesi ile birlikte oluşturulan kompozit malzemenin elastisite modülünün $1251 \mathrm{MPa}$ değerine yükseldiği görülmektedir. Bunun sebebi grafen yapisina benzer grafit nanoplakaların yüksek elastisite modülüne sahip olmasından kaynaklanmaktadır [3].

Şekil 6'da ise eklenen grafit miktarı ile birlikte kopmadaki birim şekil değiștirmenin nasıl değiştiği görülmektedir. Bu sonuçlara göre grafit yüklenmesi ile birlikte malzemelerin kopmadaki birim şekil değiştirme değerlerinin azaldığı görülmektedir. Bunun sebebi ise yüklenen $\mathrm{Gr}$ miktarı arttıkça UHMWPE kompozitlerin plastik deformasyon miktarının azalması olarak gösterilebilir [4].

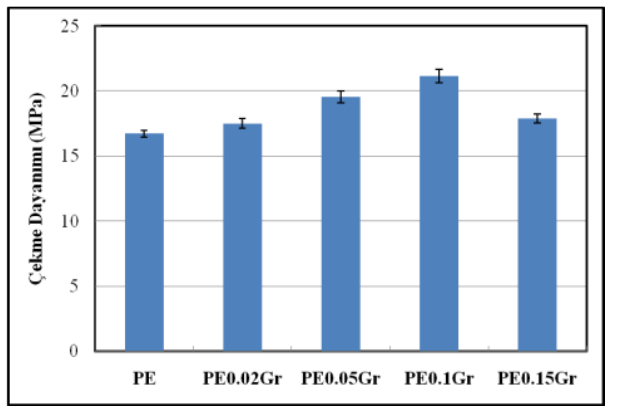

Şekil 4. PE, PE0.02Gr, PE0.05Gr, PE0.1Gr ve PE0.15Gr filmlerin çekme dayanım değerleri 


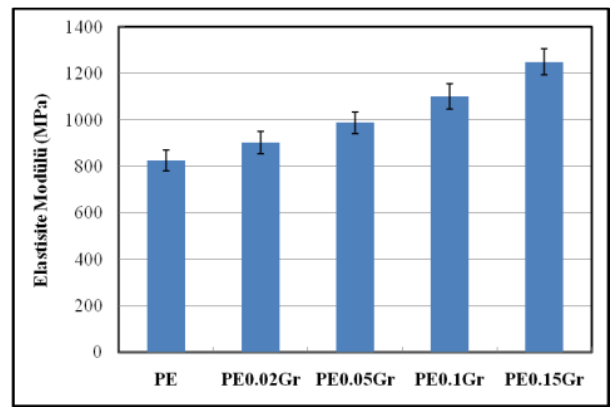

Şekil 5. PE, PE0.02Gr, PE0.05Gr, PE0.1Gr ve PE0.15Gr filmlerin eleastisite modülü değerleri

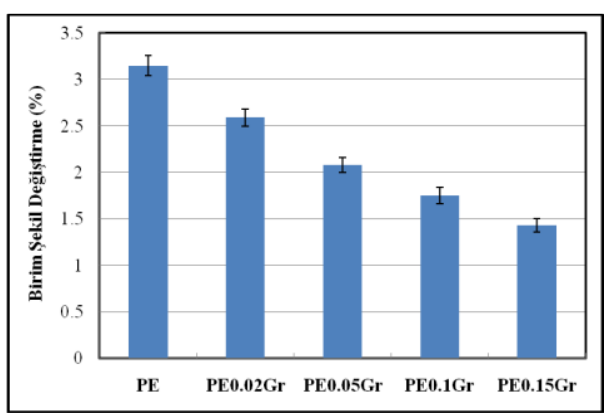

Şekil 6. PE, PE0.02Gr, PE0.05Gr, PE0.1Gr ve PE0.15Gr filmlerin kopmadaki birim şekil değiștirme (\%) değerleri

\subsection{Sertlik testi}

Sertlik deneyi sonucunda elde edilen UHMWPE ve grafit takviyeli kompozit malzemelerin mikrosertlik değerleri Şekil 7'de verilmiștir. Elde edilen mikrosertlik değerleri incelendiğinde UHMWPE içerisine grafit eklendikçe kompozit malzemelerin yüzey sertliğinin saf UHMWPE malzeme ile karşılaştırıldığında arttığı görülmektedir. $\mathrm{Bu}$ sonuçlara göre saf UHMWPE'nin sertliği $5.3 \mathrm{Hv}$ değerinden sırasıyla PE0.02Gr, PE0.05Gr, PE0.1Gr ve PE0.15Gr kompozit filmleri için 5.5, 5.8, 6.1 ve $6.4 \mathrm{Hv}$ değerlerine yükselmiştir. Üstün mekanik özelliklerinden (yüksek elastik modülüne ve sertlik değeri) dolayı grafit nanoplakalarının yükü taşıması ve yük aktarımını yapmasından dolayı mikrosertlik değerlerinin yükseldiği söylenebilir[5-6].

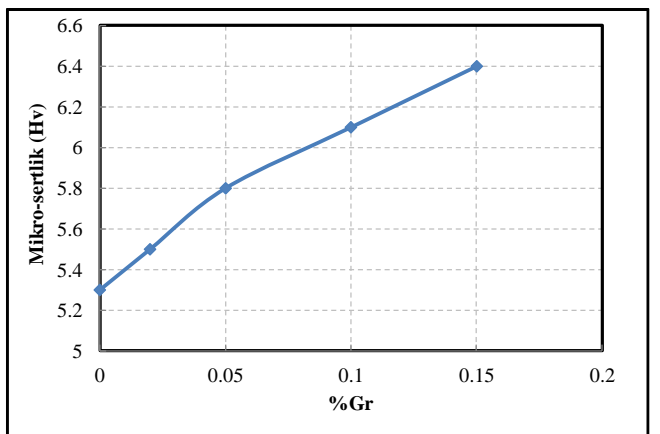

Şekil 7. PE, PE0.02Gr, PE0.05Gr, PE0.1Gr ve PE0.15Gr filmlerin mikrosertlik (Hv) değerleri

\subsection{Sürtünme Katsayısının Tespiti}

UHMWPE ve grafit nanoplaka takviyeli UHMWPE kompozit malzemelerinin yüzey pürüzlülük ölçüm değerleri Şekil 8'de verilmiștir. Şekil 8'den görüleceği üzere UHMWPE malzemeden üretilmiş malzemenin ortalama sürtünme katsayısı değeri 0.365 olarak ölçülmüştür. UHMWPE içerisine ağırlıkça 0.02, $0.05,0.1$ ve $\% 0.15$ grafit eklenmesi ile ortalama yüzey pürüzlülük katsayısı değerleri sırasıyla $0.31,0.29,0.24$ ve 0.20 olarak bulunmuştur. $\mathrm{Bu}$ sonuçlara göre UHMWPE içerisine $\mathrm{Gr}$ eklenmesiyle yüzey sürtünme katsayısı değerleri azalmaktadır.

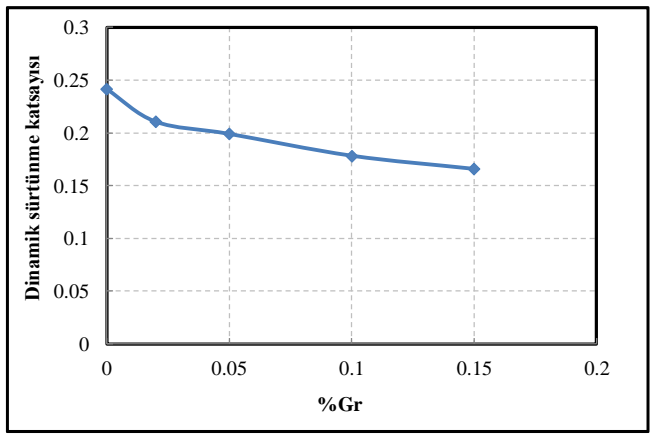

Şekil 8. PE, PE0.02Gr, PE0.05Gr, PE0.1Gr ve $\mathrm{PE0.15Gr}$ filmlerin sürtünme katsayısı değerleri

$\mathrm{Bu}$ düşüşün sebebi grafitin polimer içerisinde yağlayıcı etkisinin olmasından kaynaklanmaktadır [4, 7-8].

\subsection{Termogravimetrik Analiz (TGA)}

UHMWPE ve grafit takviyeli UHMWPE kompozit malzemelerin termogravimetrik analiz sonuçları Tablo 1'de verilmiştir. Bozunma sıcaklığ polimer malzemelerde termal kararlılığı belli eden önemli bir parametredir. Bozunma sıcaklık değerleri grafit ekledikçe düşüş göstermektedir. 
DEU FMD 21(62), 323-330, 2019

$\mathrm{Bu}$ malzemenin termal kararlılığında azalmaya sebep olmaktadır. Ayrıca Tablo 1' den UHMWPE içerisine eklenen grafit takviyesinin ağırlıkça oranı arttıkça bozulan kütle kaybı miktarının anlamlı olarak değișmediği görülmektedir.

Tablo1.UHMWPE ve grafit takviyeli UHMWPE kompozit malzemelerin TGA sonuçları

\begin{tabular}{lcc}
\hline Örnek & $\begin{array}{c}\text { Maksimum } \\
\text { Bozunma } \\
\text { Sıcaklı̆̆ }\left({ }^{\circ} \mathrm{C}\right)\end{array}$ & $\begin{array}{c}\text { Bozulan kütle } \\
(\%)\end{array}$ \\
\hline PE & 484 & 99.14 \\
PE0.02Gr & 481 & 98.96 \\
PE0.05Gr & 480 & 98.85 \\
PE0.1Gr & 480 & 98.57 \\
PE0.15Gr & 480 & 98.35 \\
\hline
\end{tabular}

\subsection{Morfolojik Analiz}

UHMWPE ve grafit takviyeli kompozit malzemelerin SEM görüntüleri Şekil 9' da verilmiştir. Grafit nanoplaka takviyesinin polimer içerisindeki dağılımında gözle görülür miktarda bir topaklanma olmadığ gözlemlenmiştir.
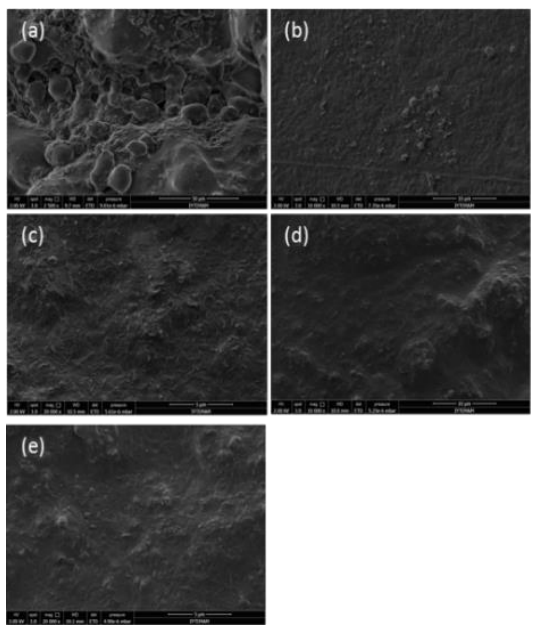

Şekil 7. a) PE, b) PE0.02Gr, c) PE0.05Gr, d) PE0.1Gr ve e) PE0.15Gr filmlerin SEM görüntüleri

\section{Sonuç}

$\mathrm{Bu}$ çalışmada ultra yüksek molekül ağırlıklı polietilene ağırlıkça farklı oranlarda grafit nanoplaka eklenmesinin elde edilen kompozit malzemelerin mekanik, termal, fiziksel ve morfolojik özelliklerine etkisi incelenmiştir. Grafit nanoplaka katkısının ağırlıkça \%0.1 oranına kadar çekme dayanımını arttırdığ gözlenmiştir. Kompozitlerde, elastisite modülünün ve mikro sertlik değerlerinin eklenen grafit nanoplaka miktarı arttıkça arttığı gösterilmiștir. Kopmadaki birim șekil değiștirme ve yüzey pürüz değerleri ise eklenen grafit miktarına bağlı olarak azalmıştır. Grafit takviyeli UHMWPE kompozit malzemelerin termal bozunma sıcaklıklarında UHMWPE'e göre bir miktar azalma görülmüștür. Grafit katkılı UHMWPE kompozit malzemelerin UHMWPE'ne klyasla artan sertlik ve elastisite modulunun ve azalan yüzey sürtünme katsayıları, grafit nanoplakaların UHMWPE tabanlı kompozitlerde özellikle biyomedikal uygulamalarda kullanılma potansiyelini göstermektedir.

\section{Kaynakça}

[1] Ramazani, S. A. A., Saremi, M. G., Amoli, B. N., Izadi, H. 2012. Production and characterization of UHMWPE/fumed silica nanocomposites, Polymer Composites, Cilt: 33(10), s. 1858-1864. 10.1002/pc.22323.

[2] Kavesh, S., Prevorsek, D. C. 1995. Ultra high strength, high modulus polyethylene spectra fibers and composites, International Journal of Polymeric Materials, Cilt: 30(1-2), s. 15-56. Doi 10.1080/00914039508031459.

[3] Chanda, M. 2006. Plastics technology handbook, Taylor and Francis, Florida,

[4] Li, C. S., Zhan, M. S., Huang, X. C., Zhou, H. 2012. Degradation behavior of ultra-high molecular weight polyethylene fibers under artificial accelerated weathering, Polymer Testing, Cilt: 31(7), s. 938-943. 10.1016/j.polymertesting.2012.06.009.

[5] Kurtz, S. M. 2009. UHMWPE biomaterials handbook: ultra high molecular weight polyethylene in total joint replacement and medical devices, Academic Press,

[6] Amoli, B. M., Ramazani, S. A. A., Izadi, H. 2012. Preparation of ultrahigh-molecular-weight polyethylene/carbon nanotube nanocomposites with a Ziegler-Natta catalytic system and investigation of their thermal and mechanical properties, Journal of Applied Polymer Science, Cilt: 125, s. E453-E461. 10.1002/app.36368.

[7] Davim, J. P., Marques, N. 2001. Evaluation of tribological behaviour of polymeric materials for 
DEU FMD 21(62), 323-330, 2019

hip prostheses application, Tribology Letters, Cilt: 11(2), s. 91-94. Doi 10.1023/A:1016607400392.

[8] Alderson, K. L., Webber, R. S., Evans, K. E. 2000 Novel variations in the microstructure of auxetic ultra-high molecular weight polyethylene. Part 2 Mechanical properties, Polymer Engineering and Science, Cilt: 40(8), s. 1906-1914. Doi 10.1002/Pen.11322.

[9] Fengzhen Liu, Yunhua Wang, Keyi Li, Licheng Jiang, Xiumei Wang, Xin Shao, et al. 2015. Graphene Oxide/Ultrahigh Molecular Weight Polyethylene Composites: Ball-Milling Preparation Mechanical Performance and Biocompatibility Effects, American Journal of Biomedical Science and Engineering, Cilt: 1(5), s. 51-57.

[10] Samad, M. A., Sinha, S. K. 2011. Dry sliding and boundary lubrication performance of a UHMWPE/CNTs nanocomposite coating on stee substrates at elevated temperatures, Wear, Cilt: 270(5-6), s. 395-402. 10.1016/j.wear.2010.11.011.

[11] Satyanarayana, N., Sinha, S. K., Ong, B. H. 2006 Tribology of a novel UHMWPE/PFPE dual-film coated onto Si surface, Sensors and Actuators aPhysical, Cilt: 128(1), s. 98-108. 10.1016/j.sna.2005.12.042.

[12] Minn, M., Sinha, S. K. 2008. DLC and UHMWPE as hard/soft composite film on $\mathrm{Si}$ for improved tribological performance, Surface \& Coatings Technology, Cilt: 202(15), s. 3698-3708 10.1016/j.surfcoat.2008.01.012.

[13] Tai, Z, Chen, Y, An, Y, Yan, X, Xue, Q. 2012 Tribological behavior of UHMWPE reinforced with graphene oxide nanosheets, Tribology Letters, Cilt: $46(1)$, s. 55-63.

[14] Chen, Y. F., Qi, Y. Y., Tai, Z. X., Yan, X. B., Zhu, F. L., Xue, Q. J. 2012. Preparation, mechanical properties and biocompatibility of graphene oxide/ultrahigh molecular weight polyethylene composites, European Polymer Journal, Cilt: 48(6), s. 1026 1033. 10.1016/j.eurpolymj.2012.03.011.

[15] Xie, X. L., Tang, C. Y., Chan, K. Y. Y., Wu, X. C., Tsui, C P., Cheung, C. Y. 2003. Wear performance of ultrahigh molecular weight polyethylene/quartz composites, Biomaterials, Cilt: 24(11), s. 1889 1896. 10.1016/S0142-9612(02)00610-5.

[16] Gong, G. F., Yang, H. Y., Fu, X. 2004. Tribological properties of kaolin filled UHMWPE composites in unlubricated sliding, Wear, Cilt: 256(1-2), s. 88-94 10.1016/S0043-1648(03)00394-6

[17] Plumlee, K., Schwartz, C. J. 2009. Improved wear resistance of orthopaedic UHMWPE by reinforcement with zirconium particles, Wear, Cilt: 267(5-8), s. 710-717. 10.1016/j.wear.2008.11.028.

[18] Mahfuz, H., Adnan, A., Rangari, V. K., Jeelani, S. 2005 Manufacturing and characterization of carbon nanotube/polyethylene composites, International Journal of Nanoscience, Cilt: 4(01), s. 55-72.

[19] Ruan, S., Gao, P., Yu, T. 2006. Ultra-strong gel-spun UHMWPE fibers reinforced using multiwalled carbon nanotubes, Polymer, Cilt: 47(5), s. $1604-$ 1611.

[20] Aoki, N., Akasaka, T., Watari, F., Yokoyama, A. 2007. Carbon nanotubes as scaffolds for cell culture and effect on cellular functions, Dental Materials Journal, Cilt: 26(2), s. 178-185.

[21] Singh, V., Joung, D., Zhai, L., Das, S., Khondaker, S. I., Seal, S. 2011. Graphene based materials: Past, present and future, Progress in Materials Science, Cilt: 56(8), s. $1178-1271$. 10.1016/j.pmatsci.2011.03.003

[22] Xiong, D. S., Lin, J. M., Fan, D. L. 2006. Wear properties of nano-Al203/UHMWPE composites irradiated by gamma ray against a CoCrMo alloy, Biomedical Materials, Cilt: 1(3), s. 175-179. 10.1088/1748-6041/1/3/013.

[23] Xiong, D. S., Lin, J. M., Fan, D. L., Jin, Z. M. 2007. Wear of nano-TiO2/UHMWPE composites radiated by gamma ray under physiological saline water lubrication, Journal of Materials Science-Materials in Medicine, Cilt: 18(11), s. 2131-2135. 10.1007/s10856-007-3199-y.

[24] Ren, X., Wang, X. Q., Sui, G., Zhong, W. H., Fuqua, M. A., Ulven, C. A. 2008. Effects of carbon nanofibers on crystalline structures and properties of ultrahigh molecular weight polyethylene blend fabricated using twin-screw extrusion, Journal of Applied Polymer Science, Cilt: 107(5), s. 2837-2845. 10.1002/app.27354.

[25] Xi, Y., Yamanaka, A., Bin, Y. Z., Matsuo, M. 2007. Electrical properties of segreated ultrahigh molecular weight polyethylene/multiwalled carbon nanotube composites, Journal of Applied Polymer Science, Cilt: 105(5), s. 2868-2876. 10.1002/app.26282.

[26] Mao, H. Y., Laurent, S., Chen, W., Akhavan, O., Imani, M., Ashkarran, A. A., et al. 2013. Graphene: Promises, Facts, Opportunities, and Challenges in Nanomedicine, Chemical Reviews, Cilt: 113(5), s. 3407-3424. 10.1021/cr300335p.

[27] Bo, X. J., Zhou, M., Guo, L. P. 2017. Electrochemical sensors and biosensors based on less aggregated graphene, Biosensors \& Bioelectronics, Cilt: 89, s. 167-186. 10.1016/j.bios.2016.05.002.

[28] Akhavan, O., Ghaderi, E., Rahighi, R. 2012. Toward Single-DNA Electrochemical Biosensing by Graphene Nanowalls, Acs Nano, Cilt: 6(4), s. 29042916. 10.1021/nn300261t.

[29] Rafiee, M. A., Rafiee, J., Wang, Z., Song, H. H., Yu, Z. Z., Koratkar, N. 2009. Enhanced Mechanical Properties of Nanocomposites at Low Graphene Content, Acs Nano, Cilt: $\quad 3(12)$ s. $\quad$ 3884-3890. 10.1021/nn9010472.

[30] Kim, H., Abdala, A. A., Macosko, C. W. 2010. Graphene/Polymer Nanocomposites, Macromolecules, Cilt: 43(16), s. 6515-6530. $10.1021 / \mathrm{ma} 100572 \mathrm{e}$.

[31] Vadukumpully, S., Paul, J., Mahanta, N., Valiyaveettil, S. 2011. Flexible conductive graphene/poly(vinyl chloride) composite thin films with high mechanical 
DEU FMD 21(62), 323-330, 2019

strength and thermal stability, Carbon, Cilt: 49(1), s. 198-205. 10.1016/j.carbon.2010.09.004.

[32] Veca, L. M., Meziani, M. J., Wang, W., Wang, X., Lu, F. S., Zhang, P. Y., et al. 2009. Carbon Nanosheets for Polymeric Nanocomposites with High Thermal Conductivity, Advanced Materials, Cilt: 21(20), s. 2088-2092. 10.1002/adma.200802317.

[33] Pang, W. C., Ni, Z. F., Chen, G. M., Huang, G. D., Huang H. D., Zhao, Y. W. 2015. Mechanical and thermal properties of graphene oxide/ultrahigh molecular weight polyethylene nanocomposites, Rsc Advances, Cilt: 5(77), s. 63063-63072. 10.1039/c5ra11826c

[34] Qiu, J. J., Wang, S. R. 2011. Enhancing Polymer Performance Through Graphene Sheets, Journal of Applied Polymer Science, Cilt: 119(6), s. 3670-3674. 10.1002/app.33068.

[35] Yang, L., Yee, W. A., Phua, S. L., Kong, J., Ding, H., Cheah, J. W., et al. 2012. A high throughput method for preparation of highly conductive functionalized graphene and conductive polymer nanocomposites, Rsc Advances, Cilt: 2(6), s. 2208-2210. 10.1039/C2RA00798C.

[36] Bhattacharyya, A., Chen, S., Zhu, M. 2014. Graphene reinforced ultra high molecular weight polyethylene with improved tensile strength and creep resistance properties, Express Polymer Letters, Cilt: 8(2), s. 74-84. 10.3144/expresspolymlett.2014.10.

[37] Tai, Z. X., Chen, Y. F., An, Y. F., Yan, X. B., Xue, Q. J. 2012. Tribological Behavior of UHMWPE Reinforced with Graphene Oxide Nanosheets, Tribology Letters, Cilt: 46(1), s. 55-63 10.1007/s11249-012-9919-6.

[38] Chen, Y., Qi, Y., Tai, Z., Yan, X., Zhu, F., Xue, Q. 2012. Preparation, mechanical properties and biocompatibility of graphene oxide/ultrahigh molecular weight polyethylene composites, European Polymer Journal, Cilt: 48(6), s. 1026 1033. 10.1016/j.eurpolymj.2012.03.011.

[39] Suñer, S., Joffe, R., Tipper, J., Emami, N. 2015. Ultra high molecular weight polyethylene/graphene oxide nanocomposites: Thermal, mechanical and wettability characterisation, Composites Part B: Engineering, Cilt: 78, S. 185-191. 10.1016/j.compositesb.2015.03.075

[40] Lahiri, D., Hec, F., Thiesse, M., Durygin, A., Zhang, C. Agarwal, A. 2014. Nanotribological behavior of graphene nanoplatelet reinforced ultra high molecular weight polyethylene composites, Tribology International, Cilt: 70, s. 165-169. 10.1016/j.triboint.2013.10.012.

[41] Berman, D., Erdemir, A., Sumant, A. V. 2014. Graphene: a new emerging lubricant, Materials Today, Cilt: 17(1), s. $31-42$ 10.1016/j.mattod.2013.12.003

[42] Chang, B. P., Akil, H. M., Nasir, R. M., and Nurdijati, S. 2013. Abrasive wear performance and antibacterial assessment of untreated and treated $\mathrm{ZnO}$ - reinforced polymer composite, Polymer Composites, 34(7), s. 1020-1032. 